\title{
Clinical Spectrum and Outcome of Childhood IgA Nephropathy - A Single Centre Experience
}

\author{
J Rumana ${ }^{1}$, A lyengar ${ }^{2}$, A Vasudevan ${ }^{3}$
}

\section{Abstract}

Background : $\lg A$ nephropathy $(\lg A N)$ is one of the most common primary glomerulonephritis worldwide. Although there is paucity of data on the clinical spectrum and outcome of child. hood $\lg A$ nephropathy in India as well as South Asia.

Objective : The aim of this retrospective study was to describe the clinical spectrum, histological findings, and outcome of the children with IgA nephropathy.

Methods : This retrospective study was conducted at Peadiatric Nephrology Department of St Johns medical college Hospital, Bangalore India. Fifteen children with histopathologically proven diagnosis of $\lg A N$ between 2010 to 2013 were included for analysis. The baseline demographics, along with clinical data, laboratory and renal biopsy details at the time of presentation and during follow up were retrieved from patient case records. Renal biopsy was classified based on Hass classification. All patients with class III and IV received immunosuppressive therapy while the rest received ACE inhibitors or no specific therapy.

Results : Among the 15 patients with $\lg A \mathrm{~N}$, male to female ratio was 1:2.The average age at presentation was 10 years (range $4 \frac{1}{2}$ years to 15 years) and the median follow up was 9 months (Inter Quartile range- 21 months). The most common clinical presentation was nephritic features with nephrotic range proteinuria $(60 \%)$ followed by isolated gross hematuria (20\%). The age at presentation was not associated with a specific clinical presentation. Ten patients had abnormal Estimated Glomerular Filtration Rate (eGFR) at the time of presentation. The renal biopsy revealed class III in 3 patients, class IV in 3 patients and class $V$ in 3 patients. There was no correlation between histopathology and clinical presentation. Class I which was most common histopathology type (seen in $40 \%$ of biopsies) was associated with various clinical presentations. At the last follow up $53 \%$ and $27 \%$ children were in complete and partial remission respectively, also $20 \%$ children progressed to Chronic Kidney Disease (CKD).

Conclusion : In this study of children with $\lg \mathrm{A} N$, the most common presentation was nephritic features with nephrotic range proteinuria and the most common histopathology feature was Class I. IgA N is associated with significant morbidity as $27 \%$ of children at last follow up were in partial remission or $20 \%$ progressed to CKD.

Key words : Immunoglobulin A nephropathy, Clinical profile, Prognosis.

\section{Introduction}

Immunoglobulin A nephropathy (IgAN) is one of the most common primary glomerulonephritis in children and adolescents worldwide. ${ }^{1,2}$ The clinical presentations of IgA nephropathy varies across the spectrum of initial renal menifestations, ranging from gross hematuria to acute nephritic syndrome ${ }^{3}$. Sometimes some patients also manifests with End stage renal disease. The prognosis of IgA N in children are not always benign sometimes it can follow the same progression as in adults ${ }^{4,5}$. Some studies have shown that ESRD will occur in $6 \%-43 \%$ of patients with IgA nephropathy over a period of 10 years $^{3}$. Environmental and genetic components are considered to contribute significantly in development and progression of the disease process. Thus the prevalence, clinical course and outcomes are highly variable when compared between different regions of the world. A higher prevalence has been noted in Asia including India. Although there is paucity of data on the clinical spectrum and outcome of childhood IgA nephropathy in India.

The aim of this study was to describe the clinical spectrum, histological findings and outcome of the children with IgA nephropathy.

\section{Materials and Methods}

This is a retrospective study of children age less than 18 years with IgA nephropathy hospitalized at St John's Medical college hospital, Bangalore, India, in the Department of Pediatric Nephrology From year 2010-2013.

Fifteen patients who had a histolopathologically proven diagnosis of IgA nephropathy (glomerular disease with IgA dominant or codominant mesangial immunoglobulin deposits excluding lupus nephritis) were followed up in this study period. Henoch scholen purpura were excluded.

The baseline demographic details, clinical details 
at onset and follow up, laboratory, biopsy findings, administered treatment, response to treatment, eGFR retrieved from patient case records. For each patient, the following information was completed from medical records: patient age at time of biopsy, sex, serum creatinine $(\mathrm{mg} / \mathrm{dL})$; urinary protein excretion $(\mathrm{g} / 24$ hours or protein/creatinine ratio); presence or absence of gross and/or microscopic hematuria; and presence or absence of hypertension (blood pressure 95th percentile for age, gender, and height on repeated measurements).

Hematuria was defined as presence of greater than five red blood cells per high-power microscopic field in a centrifuged specimen. Proteinuria was defined as amount of protein $(+)$ on dipstick testing or proteinuria greater than $0.5 \mathrm{~g} / 1.73 \mathrm{~m} 2 /$ day obtained from urine collected over 24 hours. The modified Schwartz formula was used to estimate creatinine clearance from the serum creatinine and height. Low creatinine clearance was defined as an estimated glomerular filtration rate (GFR) of, $60 \mathrm{ml} / \mathrm{min}$ per $1.73 \mathrm{~m}^{2}$ body surface area.

These patients were classified according to the initial clinical presentation ${ }^{6}$. This classification was used as follows: microscopic nephritic nephritic (hematuria + proteinuria); isolated gross hematuria; nephritic syndrome (hematuria, decrease in GFR, oliguria, hypertension, edema); nephrotic syndrome (proteinuria $>40 \mathrm{mg} / \mathrm{m}^{2} / \mathrm{h}$, hypoalbuminemia, hyperlipidemia, and edema).

Histopathologic examination was done by the same pathologist. Renal biopsies, all of which contained at least ten glomeruli, were processed for light and immunofluorescence microscopy. In light microscopy, biopsies were graded from I to $\mathrm{V}$ in increasing severity according to the Hass classification ${ }^{7}$ grades as follows: Grade I, normal histology or mild increase in mesangial matrix, without segmental lesions; Grade II, focal and segmental glomerular sclerosis, without glomerular hypercellularity or crescents; Grade III, focal (involving $<50 \%$ of glomeruli present, exclusive of globally sclerotic glomeruli) mesangial and/or endocapillary proliferative glomerulonephritis; Grade IV, diffuse (involving $>50 \%$ of glomeruli present, exclusive of globally sclerotic glomeruli) mesangial and/or endocapillary proliferative glomerulonephritis; Grade V, advanced chronic glomerulonephritis, characterized by $>40 \%$ globally sclerotic glomeruli and/or $>40 \%$ interstitial fibrosis/tubular atrophy in the cortical tissue present, regardless of other histologic features. Mesangial IgA deposits are the defining hallmark of the disease in immunofluorescence microscopy.

Patients were placed into five groups as Isolated gross hematuria, Nephritic features, Nephrotic syndrome, Nephritic-nephrotic, Chronic kidney disease. Treatment modalities seem to depend on the histopathological findings, rather than clinical features. All patients with class III and IV received immunosuppressive ther

apy, while the rest received ACE inhibitors or no specific therapy. Clinical outcome was graded as follows: complete remission (no hypertension, no urinary abnormality and no protein excretion and normal plasma creatinine concentration); Partial remission (proteinuria, $1 \mathrm{~g} / 1.73 \mathrm{~m} 2 /$ day with or without microscopic-recurrent macroscopic hematuria); Chronic kidney disease (proteinuria, $1 \mathrm{~g} / 1.73 \mathrm{~m} 2 /$ day and/or elevated plasma creatinine level).

\section{Results}

A total of 15 patients were included in this study. The average age at presentation was 10 years (range $4 \frac{1}{2}$ years to 15 years). Male to female ratio was $1: 2$ (male-33\%, female $67 \%$ ). Females were affected more often than male (table-1).

\section{Table I : Demographic Character}

$\begin{array}{lcc}\text { Age } & \text { Number } & \text { Percentage } \\ 1-5 \text { years } & 2 & 13 \% \\ \text { 6-10 years } & 6 & 40 \% \\ 11-15 \text { years } & 7 & 47 \% \\ \text { Sex } & & \\ \text { Male } & 5 & 33 \% \\ \text { Female } & 10 & 67 \%\end{array}$

Most of the patients were in regular follow-up but a few patients came irregularly. The mean follow up time among the 15 patients with IgA nephropathy was 1.5 years (2months -4 years). The most common clinical presentation was nephritic features with nephrotic range proteinuria $(60 \%)$, followed by isolated gross hematuria (20\%), One Patient present with nephrotic syndrome, one with nephritic features and one with chronic kidney disease. The age at presentation was not associated with a specific clinical presentation. Patient's eGFR was calculated from modified Schwartz formula showed abnormal eGFR at $10 \mathrm{pa}-$ tients $(66 \%)$ and normal in 5 patients (34\%) at the time of presentation (Table-II).

\section{Table II : Clinical profile (N-15), e GFR, Duration of Follow-up}

\section{Clinical Profile}

Nephritic-nephrotic

Isolated gross hematuria

Nephritic features

Nephrotic syndrome

\section{CKD e GFR}

normal

abnormal

\section{Duration of follow-up}

Mean range

Number
9
3
1
1
1
5
10

Percentage
60
20
7
7
7
34
66

Here in this study all patients underwent renal biopsy. Immunofluorescence study showed IgA deposition in the glomerular mesangium in all specimens. Light microscopic findings of biopsies were, class I in 6 patients (40\%), class III in 3 patients (20\%) 
and class IV in 3 patients (20\%) and class $\mathrm{V}$ in 3 patients (20\%). Clinical presentations were not always according to histopathological severity. Class I which was most common histopathology type (seen in $40 \%$ of biopsies) showed various clinical presentations.

Here 4 patients received ACEI alone. Steroid was given to 3 patients among them 2 received ACEI with steroid though there clinical presentations were same (nephritic nephrotic) but had different histopathology. Six patients received other cytotoxic agents like Cyclophosphamide, Azathiopurine and Dypiridamole with steroid. At the end of the follow-up 8 patients (53\%) and 4 patients $(27 \%)$ children were in complete and partial remission respectively. Twenty percent children progressed to CKD. The relationship between initial clinical findings, biopsy findings and outcome of the patients is shown in (Table III). Although $66 \%$ of patients were presented initially with abnormal eGFR only $20 \%$ has progressed to Chronic kidney disease and this 3 patients had Class $V$ biopsy findings although there clinical presentations were different.

Table III : Outcome of patients of different clinicopathologcal profile

\begin{tabular}{|c|c|c|c|c|}
\hline $\begin{array}{l}\text { Clinical } \\
\text { presentations }\end{array}$ & $\begin{array}{l}\text { Number of } \\
\text { patients }\end{array}$ & biopsy & treatment & outcome \\
\hline \multirow[t]{2}{*}{$\begin{array}{l}\text { Isolated gross } \\
\text { hematuria }(n-3)\end{array}$} & 1 patient & $\begin{array}{l}\text { Class } \\
\text { IV }\end{array}$ & Steroid & $\begin{array}{l}\text { Partial } \\
\text { remission }\end{array}$ \\
\hline & 2 patients & Class I & ACEI & $\begin{array}{l}\text { Complete } \\
\text { remission }\end{array}$ \\
\hline $\begin{array}{l}\text { Nephritic } \\
\text { Features }(n-1)\end{array}$ & 1 patient & Class I & ACEI & $\begin{array}{l}\text { Complete } \\
\text { remission }\end{array}$ \\
\hline $\begin{array}{l}\text { Nephrotic } \\
\text { Features }(n-1)\end{array}$ & 1 patient & Class I & Steroid+ACEI & $\begin{array}{l}\text { Complete } \\
\text { remission }\end{array}$ \\
\hline \multirow[t]{6}{*}{$\begin{array}{l}\text { Nephritic } \\
\text { nephrotic } \\
(n-9)\end{array}$} & 2 patients & $\begin{array}{l}\text { Class } \\
\text { IV }\end{array}$ & $\begin{array}{l}\text { Steroid+Cyclo } \\
\text { phosphamide+ } \\
\text { ACEI }\end{array}$ & $\begin{array}{l}\text { Complete } \\
\text { remission }\end{array}$ \\
\hline & 1 patients & Class I & $\begin{array}{l}\text { Steroid+azathi } \\
\text { oprine+ } \\
\text { dipyridamole }\end{array}$ & $\begin{array}{l}\text { Partial } \\
\text { remission }\end{array}$ \\
\hline & 2 patients & Class III & ACEI & $\begin{array}{l}\text { Partial } \\
\text { remission }\end{array}$ \\
\hline & 1 patient & Class I & ACEI & $\begin{array}{l}\text { Complete } \\
\text { remission }\end{array}$ \\
\hline & 1 patients & Class III & $\begin{array}{l}\text { Steroid + } \\
\text { Cyclophospha } \\
\text { mide+ACEI }\end{array}$ & $\begin{array}{l}\text { Complete } \\
\text { remission }\end{array}$ \\
\hline & 2 patients & Class V & $\begin{array}{l}\text { Steroid + } \\
\text { azathioprine+ } \\
\text { ACEI }\end{array}$ & $\begin{array}{l}\text { Progress } \\
\text { to CKD }\end{array}$ \\
\hline $\begin{array}{l}\text { Chronic } \\
\text { kidney disease }\end{array}$ & 1 patients & Class V & Steroid+ACEI & CKD \\
\hline
\end{tabular}

\section{Discussions}

This study evaluated initial clinical features, treatment modalities and outcome in children with IgAN. Fifteen patients were reviewed retrospectively over a period of 4 years.

IgAN occurs at all ages but it is most common during the second and third decades of life and uncommon under the age of 3 years. ${ }^{6,7}$. The peak incidence of IgAN in children occurs between 9-10 years of age. ${ }^{2}$ In the present study mean age of disease presentation was $10 \pm 3.5$ years, which is similar to above study. IgA nephropathy is more common in males than female ${ }^{2}$ but here male to female ratio is $1: 2$.

The clinical presentations of IgAN are not pathognomonic. The most frequent (20\%-80\%) form of presentations in children and young adult is the episodes of gross hematuria co incident with an upper respiratory tract infection. The episode usually last one to two days. Also asymptomatic microscopic hematuria can be found in $60 \%$ subjects ${ }^{1,8,9}$ and smaller number of patients may presents with clinical signs of nephritic or nephrotic syndrome $e^{10,11}$. Up to $20 \%$ of pediatric patients with IgAN have progressive disease leading ultimately to end stage renal failure. In this present study, patients were presented with nephritic nephritic $(60 \%)$, isolated gross hematuria $(20 \%)$, nephritic features $(7 \%)$, nephritic (7\%) and CKD (6\%). It is suggested that recurrent gross hematuria is a most important and common features of presentations in different studies from Europe and united States ${ }^{6}$ but here nephritic with nephrotic range protienuria is the commonest features.

Hypertention is infrequently present at disease onset and when present its severity is more and relatively easy to control. ${ }^{1,2}$. Decreased renal functions rarely present at disease onset. ${ }^{8}$ Ronkainen et al reported that hypertension at onset was present in $13 \%$ of the patients. ${ }^{1}$ In the present study about $46 \%$ patients were hypertensive. Among them one patient present with chronic kidney disease and two of those developed chronic kidney disease. Also $66 \%$ of patients were presented with decreased GFR at onset in this study.

The range of pathologic features of IgAN has been well described. In the Hass study, biopsies showing normal histology were more common in children than in adults $(27 \%, 14 \%$, respectively). ${ }^{12}$ In immunofluroscence microscopy, mesangial diffuse igA deposits are the defining hallmark of the disease. ${ }^{13}$ Immunoglobulin $\mathrm{G}$, immunoglobulin $\mathrm{M}$ and complement 3 deposition may accompany IgA. ${ }^{14}$

In the present study, renal biopsy was performed in all Patients. The immunoflurescence study showed IgA deposition in the glomerular mesangium in all specimens. Minimal histologic lesion (class I) was most commonly seen in the patients $40 \%$, Focal proliferative glomerulonephritis (class III) in 3 patients (20\%) 
and Diffuse proliferative glomerular nephritis (class IV) in 3 patients (20\%) and Chronic glomerulonephritis, $\geq 40 \%$ globally sclerotic glomeruli and/or $\geq 40 \%$ tubular atrophy or loss (class $\mathrm{V}$ ) in 3 patients (20\%). Though seven patients had minimal lesions in biopsy but 9 patients presented with features of nephritic nephrotic at onset of disease. These results suggest that the first clinical findings are not related to renal biopsy finding.

The optimal approach to the treatment of IgA nephropathy is still uncertain. There are four separate approaches to IgA nephropathy: ${ }^{15-17}$ (1) Patients with recurrent macroscopic hematuria with normal renal function, no proteinuria, and no microscopic hematuria between episodes are treated with nonspecific therapy (2) Patients with persistent proteinuria (0.5-1 g/1.73 $\mathrm{m} 2$ /day) \pm microscopic hematuria might be treated with ACEIs; (3) Patients with proteinuria (1-3 g/1.73 m2/day) persisting, despite ACEI/angiotensin receptor-blocker therapy, are treated with corticosteroid; and (4) Patients with proteinuria (3.5 g/1.73 $\mathrm{m} 2 /$ day) and/or rising serum creatinine, and/or renal biopsy with more severe histological findings may benefit from immune suppressive therapy in addition to corticosteroids. Previous studies have shown that ACEIs alone or with angiotensin receptor-blocker therapy prevent progression of renal disease in patients with IgAN. ${ }^{18,19}$ In this present study all patients were treated depending on their clinical features and histopathology findings. Here 4 patients received ACEI alone. Steroid was given to 3 patients, among them 2 patients also received ACEI. Clinical presentations of nephritic nephrotic with different histopathology, six patients received other cytotoxic agents like Cyclophosphamide, Azathiopurine and Dypiridamole with steroid.

IgAN was initially thought to follow a benign course, but it is now recognized that slow progression to ESRD occurred in up to $50 \%$ of affected patients ${ }^{16,20}$. The remaining portions entered in complete remissions or have mild hematuria or proteinuria. Its prognosis is quite variable and outcome also difficult to predict in individual cases. In this study among 15 patients 3 patients progressed to CKD. Eight (53\%) patients had complete remission and $4(27 \%)$ patients had partial remission. So careful monitoring of IgA nephropathy patients should continue.

\section{Conclusions}

In this study of children with IgA N, the most common presentation was nephritic features with nephrotic range proteinuria and the most common histopathology feature was Class I. IgA N is associated with significant morbidity as $27 \%$ of children at last follow up were in partial remission and $20 \%$ progress to CKD.

\section{Reference}

1. Ronkainen J, Ala-Houhala M, Autio-Harmainen $\mathrm{H}$, et al. Long term outcome 19 years after childhood IgA nephritis : a retrospective cohort study. Pediatric Nephrology.2006; 21(9):1266-1273.

2. Chan JC, Trachtman H. Modulating the progression in IgA Nephropathy. Nephron Clinical Practice.2006; 104(1):c61-c68.

3. Ipec Kaplan Bulet, Sevgi Mir, Betul Sozery. Outcome results in children with IgA nephropathy. Int Jour of Nephrology and Renovascular Disease. 2012; 5:23-28.

4. Wyatt R J, Krichevsky SB ,Woodford SY, et al. IgA ' Nephropathy : long term prognosis for pediatric patients. Journal pediatric .1995;127(6):913-919.

5. Wakai K, Kawamura T, Endoh M, et al. A scoring system to predict renal outcome in IgA nephropathy: from a nationwide prospective study. Nephrol Dial Transplant. 2006; 21(10) : 2800-2808.

6. Yoshikawa N. Immunoglobulin A nephropathy. In: Avner ED, Harmon WE, Niaudet $P$, editors. Pediatric Nephrology. Philadelphia, PA: Lipincott Williams and Wilkins; 2004:615-628.

7. Kaplan BS. IgA nephropathy. In : Kaplan BS, Meyers KE, editors. Pediatric Nephrology and urology: The Requisites In Pediatrics. Maryland heghts, MO : Mosby; 2004 : 137-140.

8. Fofi C, Pecci G, Galliani M, et al. IgA nephropathy: multivariate statistical analysis aimed at pretending outcome. Journal nephrology.2001; 14(4) : 280-285

9. Coppo R, D Amico G. Factors predicting progression of IgA nephropathies. Journal Nephrology. 2005; 18(5) : 503-512.

10. Hass $M$, Rahman $M H$, Cohn RA, et al. IgA nephropathy in children and adults comparison of histologic features and clinical outcome. Nephrol Dial Transplant. 2008; 23: 2537-2545.

11. Hogg RJ. Idiopathic IgA nephropathy in children. Pdiatric Nephrology. 2010; 25:823-829.

12. Hass M. Histology and Immunohistology of IgA nephropathy. Journal Nephrolgy.2005; 18(6)676-680.

13. Allen $A C$, Barratt J, Feehally J. Immunoglobulin A nephropathy. In: Neilson EG, Couser WG, editors. Immunologic Renal Disease. Philadelphia, PA: Lippincott Wil liams and Wilkins; 2001:931-947.

14. Barratt J, Feehally J. IgA nephropathy. J Am Soc Nephrol. 2005;16(7):2088-2097. 2006;69(11):1934-1938

15. Appel GB, Waldman M. The IgA nephropathy treatment dilemma.Kidney International. 2006; 69(11):1939-1944.

16. Coppo R, Amore A. IgA nephropathy. In: Geary DF, Schaefer F, editor Comprehensive Pediatric Nephrology. Maryland Heights, MO: Mosby; 2008: 291-299.

17. Praga M, Gutierrez E, Gonzalez E, Morales E, Hernandez E. Treatment of IgA nephropathy with ACE inhibitors: a randomized and controlled trial. Journal American Society of Nephrology .2003; 14:1578-1583.

18. Coppo R, Peruzzi L, Amore A, et al. IgACE: a placebo-controlled randomized trial of ACE-inhibitors (ACE-I) in children and young people with IgA nephropathy and moderate proteinuria. Journal American Society of Nephrology.2007; 18(6):1880-1888.

19. Geddes CC, Rauta V, Gronhagen-Riska C, et al. A tricontinental vie of IgA nephropathy. Nephrology Dialysis Transplant.2003; 18(8):1541-1548. 